\title{
Development and evaluation of a Japanese prediction model for low anterior resection syndrome after rectal cancer surgery
}

\author{
Masakatsu Paku \\ Osaka University \\ Osaka University \\ Shiki Fujino \\ Osaka University \\ Tsuyoshi Hata \\ Osaka University \\ Takayuki Ogino \\ Osaka University \\ Hidekazu Takahashi \\ Osaka University \\ Mamoru Uemura \\ Osaka University \\ Tsunekazu Mizushima \\ Osaka University \\ Hirofumi Yamamoto \\ Osaka University \\ Yuichiro Doki \\ Osaka University \\ Hidetoshi Eguchi \\ Osaka University
}

Norikatsu Miyoshi ( $\square$ nmiyoshi@gesurg.med.osaka-u.ac.jp )

\section{Research Article}

Keywords: rectal cancer, laparoscopy, LARS, ISR, nomogram

Posted Date: December 3rd, 2020

DOI: https://doi.org/10.21203/rs.3.rs-109435/v1 
License: (c) (i) This work is licensed under a Creative Commons Attribution 4.0 International License. Read Full License 


\section{Abstract}

Background: Low anterior resection syndrome (LARS) is the most common complication after rectal cancer resection. We aimed to identify predictive factors for LARS and to construct and evaluate a predictive model for LARS.

Methods: This retrospective study included patients with rectal cancer more than one year after laparoscopic or robotic-assisted surgery. A questionnaire was administered to evaluate the degree of LARS. Clinical characteristics were examined with univariate and multivariate logistic regressions to identify predictive factors for major LARS. The obtained data was divided into learning set and validation set. A predictive model for major LARS was constructed using the learning set, and predictive accuracy of the validation set was assessed.

Results: We reviewed a total of 160 patients with rectal cancer and divided them into a learning set $(\mathrm{n}=$ $115)$ and a validation set $(n=45)$. Univariate and multivariate analyses in the learning set showed that male (odds ratio [OR]: $2.88,95 \%$ confidence interval [95\% Cl]: $1.11-8.09, p=0.03$ ), age $<75$ years (OR: 5.87 , 95\%Cl: $1.14-47.25, p=0.03$ ) and tumors located $<8.5 \mathrm{~cm}$ from the AV (OR: $7.20,95 \% \mathrm{Cl}: 2.86-19.49, p$ $<0.01)$ were significantly related to major LARS. A prediction model based on the patients in learning set was well calibrated.

Conclusions: We found that sex, age and tumor location were independent predictors of major LARS in Japanese patients that underwent rectal cancer surgery. Our predictive model for major LARS could aid medical staff in educating and treating patients with rectal cancer before and after surgery.

\section{Background}

Colorectal cancer is one of the most prevalent types of cancer in the world.[1] Survival from colorectal cancer has increased over the past 30 years, due to advances in surgery, chemotherapy, and other medicines.[2] The standard treatment for resectable colorectal cancer is radical resection. However, in recent years, a total mesorectal excision and intersphincteric resection (ISR) have become wide-spread for treating rectal cancer.[3, 4] These techniques have reduced the local recurrence rate, but they have negatively impacted anorectal function.[5, 6]

Surgery for rectal cancer, particularly low rectal cancer, frequently causes defecation disorders, with a reported incidence of 37 to 71\%.[7-9] Defecation disorders after rectal cancer surgery are termed low anterior resection syndrome (LARS). The LARS score is an index to assess the severity of LARS,[10] and the LARS score has been correlated to quality of life.[11, 12]

Recently, a European group created a nomogram of a predictive model of LARS occurrence after rectal cancer surgery.[13] The nomogram could be an effective aid for preoperative education and counseling. However, the nomogram was created based on European patients with rectal cancer, and it is unknown if the European nomogram would adapt to Japanese patients with the same condition. 
The present study aimed to clarify the risk factors for developing LARS after rectal cancer surgery in Japan, and to develop a model for predicting LARS occurrence in Japanese patients.

\section{Methods}

We retrospectively reviewed 574 patients that underwent radical rectal cancer resections with lymph node dissections between January 2010 and July 2019 at the Osaka University Hospital. Among these patients, 199 were followed up in our outpatient clinic and completed our LARS survey questionnaire between April 2017 and July 2020. Patients were excluded when they had familial adenomatous polyposis ( 5 cases), ulcerative colitis (10 cases). Furthermore, patients less than 1 year after surgery (24 cases) were also excluded. We finally included 160 patients in this retrospective study. The obtained data was divided into learning set $(n=115$, April 2017 to May 2019) and validation set $(n=45$, June 2019 to July 2020) due to the timing of the questionnaire (Fig. 1).

\section{Patient and tumor characteristics}

We collected data on patient sex, age at surgery, body mass index (BMI), and the presence or absence of preoperative treatment. We also collected data on the tumor characteristics, including the distance from the anal verge (AV) to the anal margin of the tumor and the pathological stage, according to the TNM classification system (UICC 8th edition[14]). Furthermore, we collected data on the surgical procedure, surgery duration, and blood loss.

\section{LARS survey}

We scored the completed questionnaires and classified the severity of LARS according to a scale described previously.[10] Scores of 0 to 20 indicated no LARS, 21 to 29 indicated minor LARS, and 30 to 38 indicated major LARS We performed a multiple logistic regression analysis to identify the correlation between major LARS and the preoperative clinical factors.

\section{Statistical analysis}

All categorical data were presented as number of cases and percentages, while continuous data were shown as median and interquartile range (IQR). We performed logistic regression analysis to assess correlation between the incidence of major LARS and the distance from the AV to the anal margin of the tumor and to set the cut-off value. We also performed multiple logistic regression analyses to assess the correlation between major LARS and clinical factors.

The data were processed and analyzed with JMP Pro 14.0 (SAS Institute Inc, Cary NC). A two-tailed pvalue $<0.05$ was considered statistically significant. Univariate and multivariate analyses were performed using logistic regression analysis and odds ratios (ORs) and exact $95 \%$ confidence intervals ( $95 \% \mathrm{Cls}$ ) were calculated to evaluate absolute differences. A nomogram for major LARS was created with $R$ statistical software (version 3.5.0). 
This study was performed in accordance with the Declaration of Helsinki (1975, and revised in 2008). The study protocol was approved by the Ethics Committee of Osaka University Hospital. All study participants provided written informed consent.

\section{Results}

\section{Clinical characteristics of the study population}

Table 1 shows the patients, tumor characteristics and surgical details of 160 patients with rectal cancer post surgery. Among the 115 patinets in the learning set, the cohort included 73 males (63.5\%) and 42 females. The median age was 62 years [IQR 55-67], and 13 patients (11.3\%) were older (age $\geq 75$ ). The median BMI was $22.5 \mathrm{~kg} / \mathrm{m}^{2}$ [IQR 20.4-24.5], and 23 patients (20.0\%) were obese (BMI $\geq 25$ ). A total of 21 patients $(18.3 \%)$ received neo-adjuvant therapy, which included chemotherapy alone. The median tumor distance from the AV was $10 \mathrm{~cm}$ [IQR 6-15]. About half the patients had a tumor stage of T3 or T4 (T3, n = $44,38.3 \% ; T 4, n=11,9.6 \%)$. About half the patients had lymph node involvement $(N 1, n=30,26.1 \% ; N 2, n$ $=11,9.6 \%$ ), and 5 patients had metastases (4.3\%). Laparoscopic surgery was performed in more than $70 \%$ of patients $(n=91 ; 79.1 \%)$; robotic-assisted surgery was performed in the remaining 24 patients (20.9\%). More than half the patients underwent LAR $(n=60 ; 52.2 \%)$, and ISR was performed in 13 patients $(11.3 \%)$. Diverting ileostomy was constructed in 48 patients $(41.7 \%)$ and lateral lymph node dissection was performed in 22 patients (19.1\%). These items were compared with the learning set and the validation set. The median age at surgery was 67 years [IQR 60-72] in the validation set, which was significantly older than the learning set $(p=0.04)$. On the other hand, the propotion of those aged 75 years or older was $15.6 \%(n=7)$ in the validation set, which was equivalent to the learning set $(p=0.47)$. There were no statistically significant differences in other patient backgrounds, tumor backgrounds, or surgical details. 
Table 1 Comparison of clinical characteristics of the patients with rectal cancer between learning and validation set

\begin{tabular}{|c|c|c|c|}
\hline Variable & $\begin{array}{l}\text { Learning set } \\
\text { ( } n=115)\end{array}$ & $\begin{array}{l}\text { Validation set } \\
(n=45)\end{array}$ & p value \\
\hline \multicolumn{4}{|l|}{ Patient characteristics } \\
\hline Male sex, $\mathrm{n}(\%)$ & $73(63.5)$ & $29(64.4)$ & 0.909 \\
\hline Age at surgery, years; median [IQR] & $62[55-67]$ & $67[60-72]$ & 0.044 \\
\hline$\geq 75, \mathrm{n}(\%)$ & $13(11.3)$ & $7(15.6)$ & 0.466 \\
\hline BMI $\left(\mathrm{kg} / \mathrm{m}^{2}\right)$, median [IQR] & $22.5[20.4-24.5]$ & $22.5[19.3-25.3]$ & 0.974 \\
\hline$\geq 25, \mathrm{n}(\%)$ & $23(20.0)$ & $15(33.3)$ & 0.076 \\
\hline Neo-adjuvant therapy, $\mathrm{n}(\%)$ & $21(18.3)$ & $8(17.8)$ & 0.943 \\
\hline Chemoradiotherapy, n (\%) & $0(0)$ & $1(2.2)$ & \\
\hline Chemotherapy alone, $\mathrm{n}(\%)$ & $21(18.3)$ & $7(15.6)$ & \\
\hline \multicolumn{4}{|l|}{ Tumor characteristics } \\
\hline Tumor distance from AV, $\mathrm{cm}$; median [IQR] & $10[6-15]$ & $10[6-15]$ & 0.425 \\
\hline T stage $(0-2 / 3,4)$ & $60 / 55$ & $21 / 24$ & 0.532 \\
\hline $\mathrm{N}$ stage $(0 / 1,2)$ & $74 / 41$ & $27 / 18$ & 0.609 \\
\hline M stage $(0 / 1)$ & $110 / 5$ & $43 / 2$ & 0.979 \\
\hline \multicolumn{4}{|l|}{ Surgical details } \\
\hline Surgical approach (Robot/Laparoscopy) & $24 / 91$ & $15 / 30$ & 0.099 \\
\hline Type of surgery (ISR/HAR, LAR) & $13 / 102$ & $1 / 44$ & 0.068 \\
\hline Construction of diverting ileostomy, $\mathrm{n}(\%)$ & $48(41.7)$ & $14(31.1)$ & 0.216 \\
\hline Lateral lymph node dissection n (\%) & $22(19.1)$ & $6(13.3)$ & 0.387 \\
\hline
\end{tabular}

Values are the number of patients, unless indicated otherwise. IQR: interquartile range; BMI: Body mass index; AV: Anal verge

\section{Outcomes of the LARS survey}

The outcomes of LARS survey are shown in Table 2. The median LARS score was not significantly different between the learning set and the validation set $\triangle$ the learning set; 27 [IQR 11-34], the validation set; 25 [IQR 13-32], $p=0.80 \rrbracket$. The incidence of major LARS was over $30 \%$ in both sets, $40.9 \%(n=47)$ in the learning set and $33.3 \%(n=15)$ in the validation set. 
Table 2 Comparison of LARS score components for patients with rectal cancer between learning and validation set

\begin{tabular}{lllr}
\hline Variable & $\begin{array}{l}\text { Learning set } \\
(\mathbf{n}=\mathbf{1 1 5})\end{array}$ & $\begin{array}{l}\text { Validation set } \\
(\mathbf{n}=\mathbf{4 5})\end{array}$ & p value \\
\hline LARS score, median [IQR] & $27[11-34]$ & $25[13-32]$ & 0.796 \\
LARS categories, n (\%) & & & \\
$\quad$ No LARS & $45(39.1)$ & $15(33.3)$ & \\
$\quad$ Minor LARS & $23(20.0)$ & $15(33.3)$ & \\
$\quad$ Major LARS & $47(40.9)$ & $15(33.3)$ & \\
\hline
\end{tabular}

IQR: Interquartile range; LARS: low anterior resection syndrome

\section{Predictive model of major LARS}

To identify and construct a nomogram of predictive factors for major LARS, we performed a univariate and multivariate analysis in the learning set. A receiver operating characteristic analysis indicated the cutoff value of $8.5 \mathrm{~cm}$ for the tumor distance from the AV (area under curve (AUC):0.77, p <0.01, sensitivity: 0.73 , specificity: 0.79 ; Supplemental Fig.1).We found that major LARS was significantly associated with sex, age, tumor distance from the AV and type of surgery (Table 3 ). The multivariate analysis included factors with p-values $<0.05$ in the univariate analysis. We found that male (OR: 2.88 , $95 \% \mathrm{Cl}: 1.11-8.09, p=0.03$ ), age $<75$ years (OR: $5.87,95 \% \mathrm{Cl}: 1.14-47.25, p=0.03$ ) and tumors located $<8.5$ $\mathrm{cm}$ from the AV (OR: $7.20,95 \% \mathrm{Cl}$ : $2.86-19.49, p<0.01$ ) were independent predictors of major LARS in Table 4. We then constructed a nomogram of a predictive model for major LARS with the independent predictive variables in Fig. 2. The AUC of the nomogram for major LARS were 0.80 in the learning set and the calibration was sound. When the nomogram was applied to the validation set, the AUC was 0.76 and the calibration was also valid. 
Table 3 Univariate results for clinical characteristics associated with major LARS in learning set

\begin{tabular}{|c|c|c|c|c|c|}
\hline \multirow{2}{*}{ Variable } & \multirow{2}{*}{ Category } & \multirow{2}{*}{$\begin{array}{c}\text { No. of } \\
\text { patients }\end{array}$} & \multirow{2}{*}{$\begin{array}{c}\text { Incidence of major } \\
\text { LARS (\%) }\end{array}$} & \multicolumn{2}{|c|}{ Univariate analysis $^{\star}$} \\
\hline & & & & OR $(95 \% \mathrm{Cl})$ & p-value \\
\hline \multirow[t]{2}{*}{ Sex } & Male & 73 & 47.9 & $2.947(1.297-7.127)$ & 0.009 \\
\hline & Female & 42 & 23.8 & Reference & \\
\hline \multirow[t]{2}{*}{ Age, $y$} & $<75$ & 102 & 42.2 & $4.008(1.010-26.765)$ & 0.048 \\
\hline & $\geq 75$ & 13 & 15.4 & Reference & \\
\hline \multirow[t]{2}{*}{$\mathrm{BMI}, \mathrm{kg} / \mathrm{m}^{2}$} & $<25.0$ & 92 & 40.2 & $1.264(0.495-3.411)$ & 0.631 \\
\hline & $\geq 25.0$ & 23 & 34.8 & Reference & \\
\hline \multirow{2}{*}{$\begin{array}{l}\text { Tumor distance from } \\
\mathrm{AV}, \mathrm{cm}\end{array}$} & $<8.5$ & 46 & 67.4 & $9.375(4.193-22.185)$ & $<.001$ \\
\hline & $\geq 8.5$ & 14 & 20.3 & Reference & \\
\hline \multirow[t]{2}{*}{ Type of surgery } & ISR & 102 & 34.3 & $6.381(1.818-29.840)$ & 0.003 \\
\hline & HAR, LAR & 13 & 76.9 & Reference & \\
\hline
\end{tabular}

'Mann-Whitney's U test; OR: odds ratio; Cl: confidence interval; LARS: low anterior resection syndrome; BMI: body mass index; AV: anal verge, HAR: high anterior resection, LAR: low anterior resection, ISR: intersphincteric resection

Table 4 Multivariate analysis of clinical characteristics associated with major LARS in learning set

\begin{tabular}{lcc}
\hline \multirow{2}{*}{ Factors } & \multicolumn{2}{c}{ Multivariate analysis $^{\mathrm{a}}$} \\
\cline { 2 - 3 } & $\mathrm{OR}(95 \% \mathrm{Cl})$ & $\mathrm{p}$ value \\
\hline Male & $2.883(1.108-8.092)$ & 0.030 \\
Age $<75$ years & $5.871(1.138-47.250)$ & 0.033 \\
Tumor distance from AV $<8.5 \mathrm{~cm}$ & $7.201(2.856-19.488)$ & $<.001$ \\
Intersphincteric resection & $2.518(0.565-14.145)$ & 0.233 \\
\hline
\end{tabular}

'Logistic regression analysis; OR: odds ratio; $\mathrm{Cl}$ : confidence interval; LARS: low anterior resection syndrome; AV: anal verge

\section{Discussion}

Rectal cancer surgery is frequently associated with complications.[15-17] Defecation disorders are among the most frequent complications after rectal cancer surgery. The Japanse treatment guidelines recommend total mesorectal excision for patients with rectal cancer.[18] In addition, we are also actively working on lateral lymph node dissection and ISR to prevent local recurrences. These surgical treatments cause bowel dysfunction due to damage of the anal sphincter muscle and a reduction in rectal volume. [19-21] On the other hand, preoperative radiation therapy is recommended for patients with advanced rectal cancer in Western countries, and it has been reported that the radiation therapy also leads to defecation disorders.[13,22] The incidence of major LARS after rectal cancer surgery has been reported to be more than $40 \%$ [22-24], and the incidence of major LARS was similar in this study. 
Defecation disorders impose limits on daily life activities and mental stress. $[25,26]$ It is considered necessary to treat or prevent defectation disorders after rectal cancer surgery. One study reported that sacral nerve stimulation therapy could effectively alleviate defection disorders.[27] However, there has been no evidence of an effective treatment for LARS. Recently, it has been reported that a nomogram may be effective in preventing complications. $[28,29]$ In addition, the nomogram may be beneficial for counseling patients. Therefore, we expect that our nomogram can play an important role for LARS therapy.

We identified three predictive factors for major LARS: male, age, and tumors location. These factors were also identified as predictors of defecation disorders in other reports. A feature of the characteristics of the nomogram, the influence of each factor can be visualized, and as shown in Fig. 2, it can be seen that the distance from the anal margin to the tumor has the strongest effect on major LARS occurrences. This result was similar in the nomogram reported by Battersby NJ, et al..[13] These results suggested that LARS severity might depend on the volume of the remaining rectum.

We found that age also strongly affected the development of major LARS in our nomogram. Older individuals have a weak anal sphincter muscle, which prevents control of gas or stool passage.[30] Therefore, fecal incontinence after rectal cancer surgery might be expected to occur more frequently in older patients. However, interestingly, we found that younger patients tended to have higher LARS scores in this study, consistent with findings in the previous European study.[13] When compared by age, there was no apparent difference in clinical characteristics, as shown in Supplemental table 1. On the other hand, comparing the results of the LARS survey, younger patients had higher scores than older patients in the question about the sense of urgency in defecation (Q5), although they showed little or no differences in the scores for questions 1-3, as shown in Supplemental table 2. This result suggested that younger patients felt more fecal urgency than older patients, despite the fact that rectal cancer surgery can cause stool and fecal incontinence, regardless of age.

Gender was also a correlating factor as well as the other report.[13] In the present study, men were more likely to develop major LARS. However, men generally have a narrower pelvic floor than women, which makes it more difficult to manipulate and puts more external stress on the surrounding tissues, including the pelvic floor muscles, which may have led to defecation problems. On the other hand, the European nomogram suggests that women are more likely to develop major LARS and to have defecation disorders due to damage to the pelvic floor muscles caused by childbirth. Thus, the nomogram has a problem that the results may differ depending on the background of the subject, and the application of the nomogram needs to be carefully examined. In fact, the AUC of the European nomogram was 0.60 in the present study of 160 patients, and our nomogram showed higher accuracy.

The present study had some potential limitations. First, it was a single center study, and 47 patients developed major LARS in the learning set. This number might have been insufficient to create a predictive model for major LARS. Furthermore, the number of verifications of our predictive model was also an 
insufficient number of cases. In the future, we would like to verify our predictive model and conduct a multicenter prospective study.

\section{Conclusions}

We identified three independent predictors of major LARS for Japanese patients that undergo rectal cancer surgery: sex, the age at surgery, the location of the tumor. We also constructed and validated a nomogram to predict major LARS from the above results. In the future, we will examine the applicability of the model developed in this study to other institutions and the impact of this model on rectal cancer treatment.

\section{List Of Abbreviations}

ISR: intersphincteric resection; LARS: low anterior resection syndrome; BMI: body mass index; AV: anal verge; IQR: interquartile range; OR: odds ratio; $95 \% \mathrm{Cl}$ : 95\% confidence interval; AUC: area under curve

\section{Declarations}

Ethics approval The study protocol was approved by the Ethics Committee of Osaka University Hospital.

Consent to participate All study participants provided written informed consent. The authors declare that they have no conflict of interest.

Consent for publication Consent for publication was obtained from the all study participants.

Availability of data and materials The datasets used and/or analysed during the current study available from the corresponding author on reasonable request.

Competing interest The authors declare that they have no conflict of interest.

Funding Not applicable

\section{Authors' contributions}

Conception and design of the study: Paku, Miyoshi, Fujino

Analysis and interpretation of data: Paku, Miyoshi, Fujino, Mizushima

Acquisition of data: Paku, Miyoshi, Fujino, Hata, Ogino, Takahashi

Drafting of manuscript: Paku, Miyoshi, Fujino, Uemura, Mizushima

Critical revision of manuscript: Paku, Miyoshi, Fujino, Yamamoto, Doki

Final approval of the article: Eguchi 


\section{References}

1. Ferlay J, Soerjomataram I, Dikshit R, Eser S, Mathers C, Rebelo M, Parkin DM, Forman D, Bray F: Cancer incidence and mortality worldwide: sources, methods and major patterns in GLOBOCAN 2012. Int J Cancer 2015, 136(5):E359-386.

2. Rawla P, Sunkara T, Barsouk A: Epidemiology of colorectal cancer: incidence, mortality, survival, and risk factors. Prz Gastroenterol 2019, 14(2):89-103.

3. Hohenberger W, Weber K, Matzel K, Papadopoulos T, Merkel S: Standardized surgery for colonic cancer: complete mesocolic excision and central ligation-technical notes and outcome. Colorectal Dis 2009, 11(4):354-364; discussion 364-355.

4. Dimitriou N, Griniatsos J: Complete mesocolic excision: Techniques and outcomes. World J Gastrointest Oncol 2015, 7(12):383-388.

5. Yamada K, Ogata S, Saiki Y, Fukunaga M, Tsuji Y, Takano M: Functional results of intersphincteric resection for low rectal cancer. Br J Surg 2007, 94(10):1272-1277.

6. Ito M, Saito N, Sugito M, Kobayashi A, Nishizawa Y, Tsunoda Y: Analysis of clinical factors associated with anal function after intersphincteric resection for very low rectal cancer. Dis Colon Rectum 2009, 52(1):64-70.

7. Nakahara S, Itoh H, Mibu R, Ikeda S, Oohata Y, Kitano K, Nakamura Y: Clinical and manometric evaluation of anorectal function following low anterior resection with low anastomotic line using an EEA $^{\mathrm{m}}$ stapler for rectal cancer. Diseases of the Colon \& Rectum 1988, 31(10):762-766.

8. Oya M, Komatsu J, Takase $\mathrm{Y}$, Nakamura T, Ishikawa $\mathrm{H}$ : Comparison of defecatory function after colonic J-pouch anastomosis and straight anastomosis for stapled low anterior resection: results of a prospective randomized trial. Surg Today 2002, 32(2):104-110.

9. van Duijvendijk P, Slors JF, Taat CW, van Tets WF, van Tienhoven G, Obertop H, Boeckxstaens GE: Prospective evaluation of anorectal function after total mesorectal excision for rectal carcinoma with or without preoperative radiotherapy. Am J Gastroentero/ 2002, 97(9):2282-2289.

10. Emmertsen KJ, Laurberg S: Low anterior resection syndrome score: development and validation of a symptom-based scoring system for bowel dysfunction after low anterior resection for rectal cancer. Ann Surg 2012, 255(5):922-928.

11. van Heinsbergen M, Van der Heijden JAG, Stassen LP, Melenhorst J, de Witte E, Belgers EH, Maaskant-Braat AJG, Bloemen JG, Bouvy ND, Janssen-Heijnen ML et al: The low anterior resection syndrome in a reference population: prevalence and predictive factors in the Netherlands. Colorectal Dis 2020, 22(1):46-52.

12. Juul T, Ahlberg M, Biondo S, Espin E, Jimenez LM, Matzel KE, Palmer GJ, Sauermann A, Trenti L, Zhang $W$ et al: Low anterior resection syndrome and quality of life: an international multicenter study. Dis Colon Rectum 2014, 57(5):585-591. 
13. Battersby NJ, Bouliotis G, Emmertsen KJ, Juul T, Glynne-Jones R, Branagan G, Christensen P, Laurberg S, Moran BJ: Development and external validation of a nomogram and online tool to predict bowel dysfunction following restorative rectal cancer resection: the POLARS score. Gut 2018, 67(4):688-696.

14. Brierley JG, MK., Wittekind, C., editors.: The TNM classification of malignant tumours. 8. Oxford: Wiley Blackwell 2017.

15. Pak J, Uemura M, Fukuda Y, Miyake M, Ikeda M, Nishikawa K, Miyamoto A, Hirao M, Nakamori S, Sekimoto M: Predictors of High-Output Stoma After Low Anterior Resection With Diverting lleostomy for Rectal Cancer. International Surgery 2018, 102(7-8):313-317.

16. Pak J, Ikeda M, Uemura M, Miyake M, Nishikawa K, Miyamoto A, Miyazaki M, Hirao M, Nakamori S, Sekimoto M: Risk factors for bleeding in patients receiving fondaparinux after colorectal cancer surgery. Journal of the anus, rectum and colon 2018, 1(4):131-135.

17. Alavi M, Wendel CS, Krouse RS, Temple L, Hornbrook MC, Bulkley JE, McMullen CK, Grant M, Herrinton LJ: Predictors of Bowel Function in Long-term Rectal Cancer Survivors with Anastomosis. Annals of surgical oncology 2017, 24(12):3596-3603.

18. Hashiguchi Y, Muro K, Saito Y, Ito Y, Ajioka Y, Hamaguchi T, Hasegawa K, Hotta K, Ishida H, Ishiguro M et al: Japanese Society for Cancer of the Colon and Rectum (JSCCR) guidelines 2019 for the treatment of colorectal cancer. Int J Clin Oncol 2020, 25(1):1-42.

19. Kauff DW, Kronfeld K, Gorbulev S, Wachtlin D, Lang H, Kneist W: Continuous intraoperative monitoring of pelvic autonomic nerves during TME to prevent urogenital and anorectal dysfunction in rectal cancer patients (NEUROS): a randomized controlled trial. BMC Cancer 2016, 16:323.

20. Wallner C, Lange MM, Bonsing BA, Maas CP, Wallace CN, Dabhoiwala NF, Rutten HJ, Lamers WH, Deruiter $\mathrm{MC}$, van de Velde $\mathrm{CJ}$ : Causes of fecal and urinary incontinence after total mesorectal excision for rectal cancer based on cadaveric surgery: a study from the Cooperative Clinical Investigators of the Dutch total mesorectal excision trial. J Clin Oncol 2008, 26(27):4466-4472.

21. Peeters KC, van de Velde CJ, Leer JW, Martijn H, Junggeburt JM, Kranenbarg EK, Steup WH, Wiggers T, Rutten HJ, Marijnen CA: Late side effects of short-course preoperative radiotherapy combined with total mesorectal excision for rectal cancer: increased bowel dysfunction in irradiated patients-a Dutch colorectal cancer group study. J Clin Oncol 2005, 23(25):6199-6206.

22. Chen TY, Wiltink LM, Nout RA, Meershoek-Klein Kranenbarg E, Laurberg S, Marijnen CA, van de Velde CJ: Bowel function 14 years after preoperative short-course radiotherapy and total mesorectal excision for rectal cancer: report of a multicenter randomized trial. Clinical colorectal cancer 2015, 14(2):106-114.

23. Dulskas A, Kavaliauskas P, Pilipavicius L, Jodinskas M, Mikalonis M, Samalavicius NE: Long-term bowel dysfunction following low anterior resection. Scientific reports 2020, 10(1):11882-11882.

24. Sturiale A, Martellucci J, Zurli L, Vaccaro C, Brusciano L, Limongelli P, Docimo L, Valeri A: Long-term functional follow-up after anterior rectal resection for cancer. Int J Colorectal Dis 2017, 32(1):83-88. 
25. Chen TY, Emmertsen KJ, Laurberg S: What Are the Best Questionnaires To Capture Anorectal Function After Surgery in Rectal Cancer? Curr Colorectal Cancer Rep 2015, 11:37-43.

26. Eid Y, Bouvier V, Menahem B, Thobie A, Dolet N, Finochi M, Renier M, Gardy J, Launoy G, Dejardin 0 et al: Digestive and genitourinary sequelae in rectal cancer survivors and their impact on health-related quality of life: Outcome of a high-resolution population-based study. Surgery 2019, 166(3):327-335.

27. Chan MK, Tjandra JJ: Sacral nerve stimulation for fecal incontinence: external anal sphincter defect vs. intact anal sphincter. Dis Colon Rectum 2008, 51(7):1015-1024; discussion 1024-1015.

28. Watanabe Y, Miyoshi N, Fujino S, Takahashi H, Haraguchi N, Hata T, Matsuda C, Yamamoto H, Doki Y, Mori $\mathrm{M}$ et al: Cumulative Inflammation Could Be a Risk Factor for Intestinal Failure in Crohn's Disease. Digestive Diseases and Sciences 2019, 64(8):2280-2285.

29. Sasaki M, Miyoshi N, Fujino S, Ogino T, Takahashi H, Uemura M, Matsuda C, Yamamoto H, Mizushima T, Mori $\mathrm{K}$ et al: The Geriatric Nutritional Risk Index predicts postoperative complications and prognosis in elderly patients with colorectal cancer after curative surgery. Scientific Reports 2020, 10:10744.

30. Nakanishi N, Tatara K, Naramura H, Fujiwara H, Takashima Y, Fukuda H: Urinary and fecal incontinence in a community-residing older population in Japan. J Am Geriatr Soc 1997, 45(2):215219.

\section{Figures}




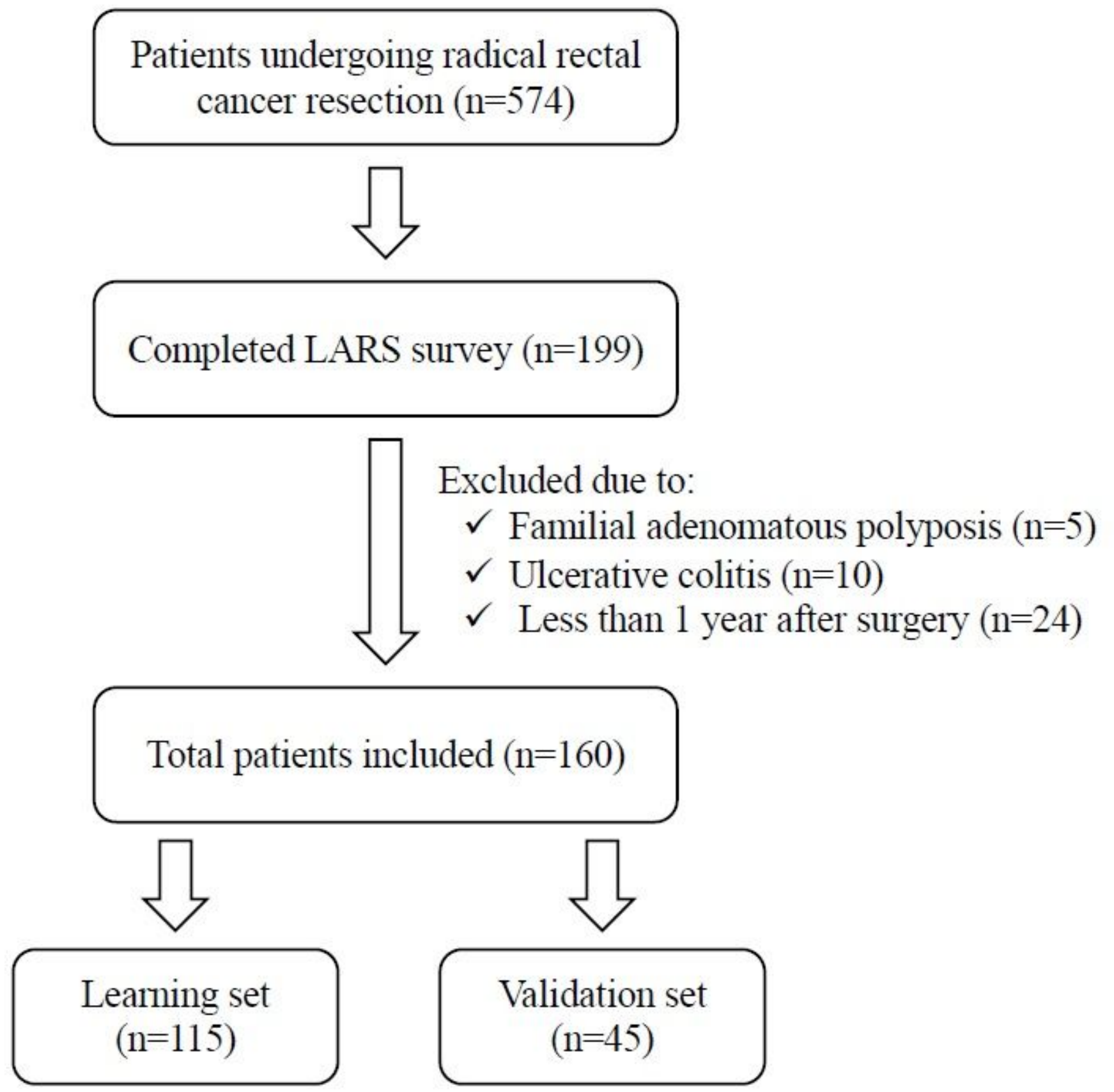

Figure 1

Patients selection process for this study. 


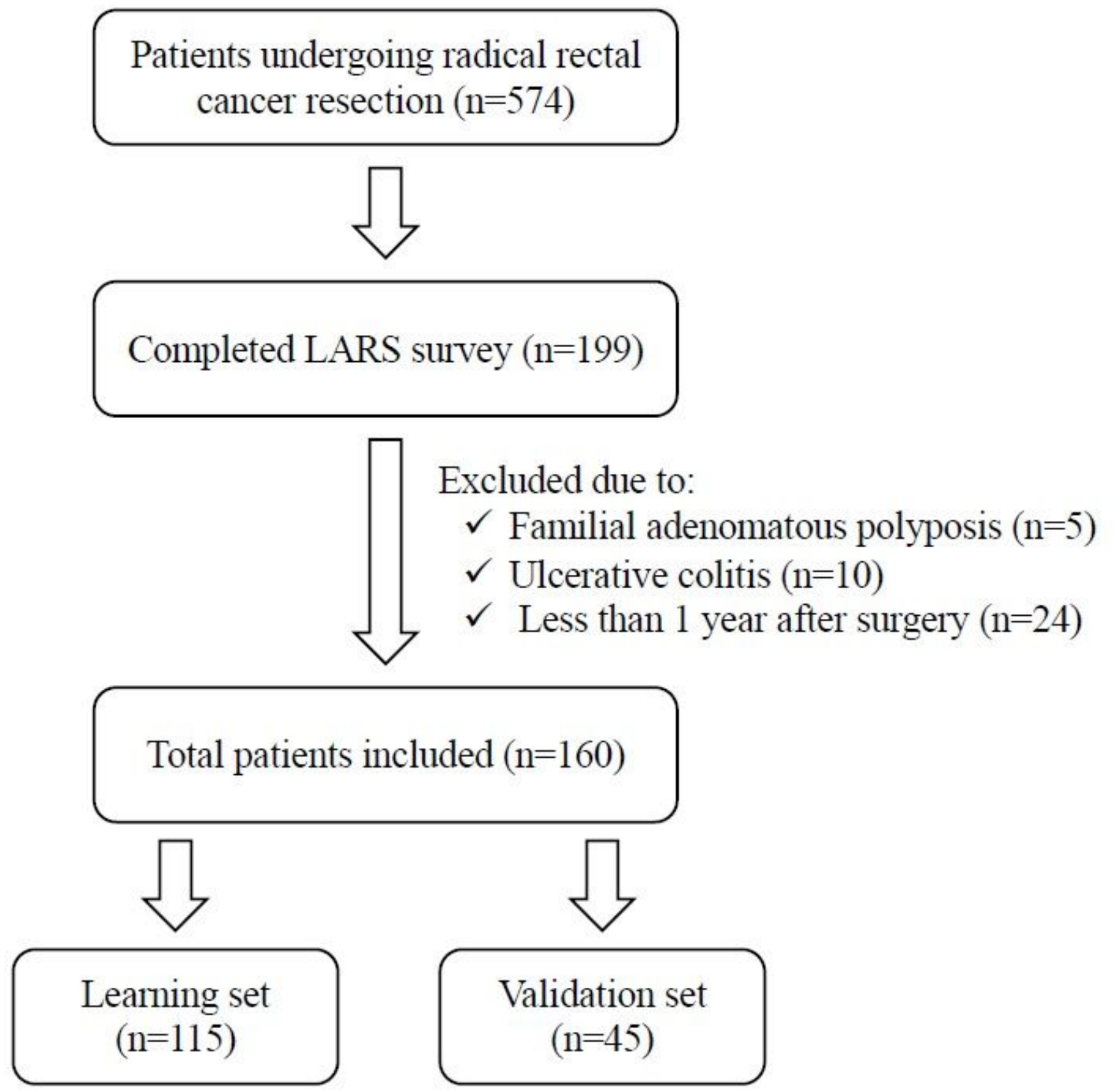

Figure 1

Patients selection process for this study. 
Points

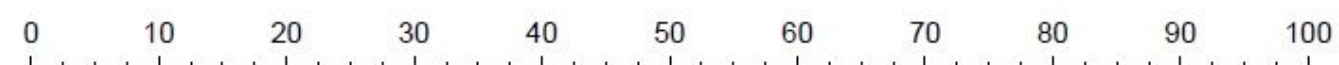

Sex

Male

Female

$\mathrm{AV}(\mathrm{cm})$

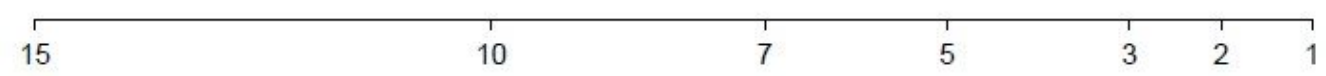

Age (years)

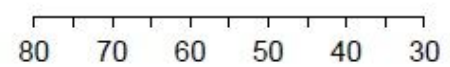

Total points

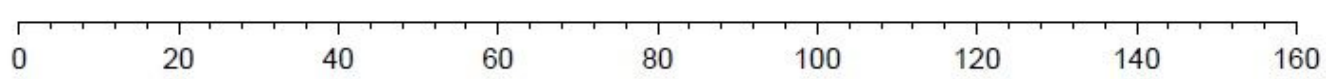

Predicting probability

0.05

0.1

0.2

0.3

$\begin{array}{llll}0.4 & 0.5 & 0.6 & 0.7\end{array}$

0.8

0.9

\section{Figure 2}

Nomogram for prediction of major LARS. LARS: low anterior resection syndrome; AV: anal verge 


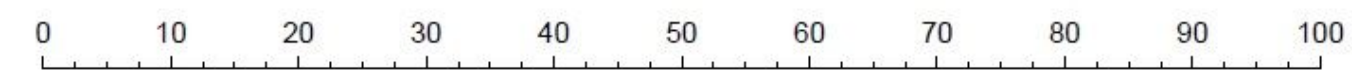

Sex

Male

Female

AV (cm)

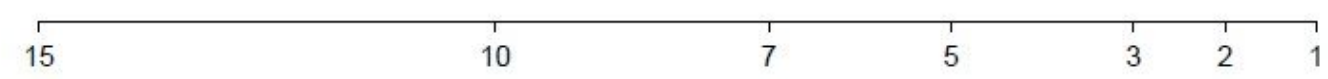

Age (years)

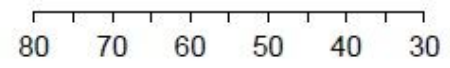

Total points

$\begin{array}{lllllll} & & 1 & 1 & 1 & 1 & 1\end{array}$

Predicting probability

0.05

0.1

0.2

0.3

$\begin{array}{llll}0.4 & 0.5 & 0.6 & 0.7\end{array}$

0.8

\section{Figure 2}

Nomogram for prediction of major LARS. LARS: low anterior resection syndrome; AV: anal verge

\section{Supplementary Files}

This is a list of supplementary files associated with this preprint. Click to download.

- Supplementalfigure1.pdf

- Supplementalfigure1.pdf

- Supplementaltables.docx

- Supplementaltables.docx 